\title{
DISTRIBUIÇÃO DE BIOMPHALARIA GLABRATA (SAY, 1818) (PULMONATA, PLANORBIDAE) NO ESTADO DE SÃO PAULO, BRASIL
}

\author{
Horacio Manuel Santana Teles* \\ Jorge Faria Vaz*
}

\begin{abstract}
TELES, H. M. S. \& VAZ, J. F. Distribuição de Biomphalaria glabrata (Say, 1818) (Pulmonata, Planorbidae) no Estado de São Paulo, Brasil. Rev. Saúde públ., S. Paulo, 21:508-12, 1987.

RESUMO: São apresentadas informações atualizadas sobre a distribuição geográfcia de Biomphalaria glabrata (Say, 1818) no Estado de São Paulo (Brasil), em razão do importante papel que tal espécie de planorbídeo desempenha na epidemiologia da esquistossomose mansônica. Registrou-se que a maior área colonizada por $\boldsymbol{B}$. glabrata corresponde à região abrangida pelos municípios dos limites oeste-sudoeste do Estado, enquadrada na bacia hidrográfica do Rio Paranapanema. São comentados os prováveis mecanismos envolvidos na dispersão do caramujo.
\end{abstract}

UNITERMOS: Biomphalaria glabrata, distribuição geográfica. Esquistossomose mansônica. Vigilância epidemiológica.

\section{INTRODUÇÃO}

A ocorrência de Biomphalaria glabrata (Say, 1818) nas coleções hídricas do Estado de São Paulo foi assinalada pela primeira vez por Rey $^{13}$ no Município de Ourinhos. A seguir Piza e Ramos ${ }^{11}$ e Corrêa e col. ${ }^{3}$ demonstraram a presença da espécie em maior número de municípios. Contudo, só em 1972, Piza e col. ${ }^{12}$, após a condução de inquérito malacológico mais pormenorizado, concluíram que o domínio territorial do caramujo abrangia a área coberta por 18 municípios: Assis, Cândido Mota, Cerquilho, Coronel Macedo, Fartura, Florínea, Ibirarema, Ipauçu, Itaberá, Itapeva, Itaporanga, Ourinhos, Ribeirão do Sul, Salto Grande, Santa Cruz do Rio Pardo, Taguaí, Taquarituba e Xavantes.

Além desses municípios, B. glabrata foi posteriormente assinalada no Município de São Paulo, habitando um lago e córrego tributário do Rio Pinheiros, dentro da área ocupada pelo "Campus" da Universidade de São Paulo (USP) (Artigas e Camargo'). Tempos depois, Guarita e col..$^{5}$ (1981) tornaram a encontrar uma população do caramujo, dessa vez em um alagado próximo ao leito do Rio Pinheiros, junto à Ponte do Morumbi. Mais recentemente, Teles ${ }^{15}$ (1986) discorreu sobre o reencontro de $B$. glabrata em sintopia com Biomphalaria tenagophila (d'Orbigny, 1835), agora no reservatório da Represa Billings.
No Município de Campinas, B. glabrata alcançou o meio ambiente devido a um acidente verificado nos laboratórios da Universidade de Campinas (UNICAMP) (Dias e Genaro ${ }^{4}$ ) enquanto que, em Ribeirão Preto, exemplares albinos chegaram a ser comercializados como elementos de decoração para aquários domésticos $\left(\right.$ Teles $\left.^{15}\right)$. Kawazoe e Pinto ${ }^{6}$ relataram a introdução acidental de desovas de $B$. glabrata em viveiros situados na cidade de Taubaté, cujos adultos demonstraram capacidade de manutenção do ciclo de Schistosoma mansoni Sambon, 1907 entre reservatórios silvestres.

Afora estes relatos não existem outras citações acerca do encontro deste importante hospedeiro intermediário de $S$. mansoni em outros municípios do Estado.

A espécie B. glabrata é referida pela maioria dos autores como o hospedeiro melhor adaptado à veiculação de $S$. mansoni, ao ponto de Paraense e col." afirmarem que "como ocorre habitualmente, a presença de $B$. glabrata coincide com a transmissão de xistosomose". Assim, parece fundamental a permanente atualização dos informes sobre a distribuição geográfica desta espécie de caramujo, através da qual são classificados epidemiologicamente os casos de esquistossomose. Por outro lado, a identificação dos mecanismos envolvidos na dispersão do planorbídeo possibilita o estabelecimento de medidas preventivas

* Superintendência de Controle de Endemias (SUCEN) - Rua Paula Souza, 166 - 01027 - São Paulo, SP - Brasil. 
que visem a dificultar a ampliação dos domínios de $B$. glabrata. Tomando como base estas premissas, o presente trabalho pretende atualizar a distribuição de $B$. glabrata em São Paulo, além de apresentar uma breve discussão sobre a dispersão da espécie dentro do contexto hídrico do território paulista.

\section{MATERIAL E METODOS}

Com as profundas alterações sofridas no perfil geográfico e ambiental e pela descrição de novas espécies de bionfalárias verificada nos últimos anos, a Superintendência de Controle de Endemias (SUCEN) resolveu iniciar em setembro de 1981 um levantamento da malacofauna límnica que alcançou coleções hídricas em todos os $\mathbf{5 7 2}$ municípios que compõem o Estado de São Paulo, objetivando a redimensionar os dados sobre a distribuição dos hospedeiros de $S$. mansoni. Os trabalhos de campo foram concluídos em março de 1986.

Durante este período foram remetidos, ao Laboratório de Malacologia da SUCEN, 3.160 lotes de caramujos, contando com 10 a 70 exemplares de bionfalárias por lote. De cada um destes, selecionaram-se 10 exemplares que se encontram conservados com conchas e partes moles, estas últimas fixadas em líquido de Railliet e Henry modificado, mantidas no acervo da instituição.

Para a coleta do material estudado as equipes de campo observaram a conduta formulada por Vaz e col. ${ }^{16,17,18}$, correspondendo à realização de duas pesquisas em coleções hídricas distintas a cada $100 \mathrm{~km}^{2}$, sem estipular a quantidade de caramujos obtidos, e dando preferência às águas que possuíssem residências nas proximidades. Apenas após a visita de seis coleções hídricas sem constatar a existência de caramujos, foi dado "ausência de planorbídeos" para a área. Os registros dessas atividades estão arquivados no Laboratório em impresso próprio.

Aos 3.160 lotes examinados foram acrescidos mais três, coletados em novembro de 1986, dois procedentes de Itaí e um de Riversul.

O conteúdo de cada lote constituído por conchas e partes moles extraídas em água aquecida $\left(70^{\circ} \mathrm{C}\right)$ foi identificado mediante a observação de pormenores conquiliológicos e da anatomia do sistema genital.

\section{RESULTADOS}

Entre os 3.163 lotes considerados, B. glabrata pôde ser confirmada em 224 (7,08\%), somando 7.941 exemplares procedentes de coleções hídricas localizadas em 24 municípios relacionados na Tabela. A maior área de colonização de $B$. glabrata corresponde à região abrangida pelos municípios dos limites oeste-sudoeste do Estado, mantendo-se praticamente inalterada se comparada com a disposição coligida por Piza e col. ${ }^{12}$, ficando pois, delimitada às terras enquadradas pela bacia hidrográfica do Rio Paranapanema (Figura 1).

\section{TABELA}

Municípios do Estado de São Paulo com criadouros de Biomphalaria glabrata, pesquisados no período compreendido entre setembro de 1981 e março de 1986.

\begin{tabular}{lrr}
\hline Municípios & Lotes & Exemplares \\
\hline Assis & 28 & 1.519 \\
Barão de Antonina & 3 & 48 \\
Cândido Mota & 4 & 85 \\
Cerquilho & 2 & 90 \\
Coronel Macedo & 1 & 11 \\
Fartura & 31 & 353 \\
Ibirarema & 6 & 483 \\
Ipauçu & 8 & 262 \\
Itaberá & 3 & 9 \\
Itaí* & 2 & 24 \\
Itapeva & 4 & 104 \\
Ourinhos & 82 & 3.714 \\
Palmital & 7 & 317 \\
Porto Feliz & 3 & 141 \\
Ribeirão do Sul & 1 & 102 \\
Ribeirão Preto & 1 & 3 \\
Riversul* & 1 & 10 \\
Salto Grande & 3 & 45 \\
Santa Cruz do Rio Pardo & 2 & 34 \\
São Paulo & 3 & 111 \\
São Pedro do Turvo & 1 & 61 \\
Taguai & 15 & 69 \\
Taquarituba & 1 & 16 \\
Xavantes & 224 & 7.941 \\
Total & & 330 \\
Par & & \\
\hline
\end{tabular}

* Municípios incluídos em novembro de 1986.

Ao longo da bacia formada pelo Rio Tietê e seus afluentes, $B$. glabrata tem habitats nos Municípios de São Paulo, Porto Feliz e Cerquilho, todos dispostos à margem esquerda. No Município de São Paulo, B. glabrata incorporou um lote coletado no reservatório da Represa Billings, devendo-se salientar que, em outras oportunidades, populaçōes deste caramujo ocuparam pontos próximos às margens do Rio Pinheiros, tais como: "Campus" da Universidade de São Paulo e Ponte do Morumbi ${ }^{5}$.

Já em Ribeirão Preto, município interposto no complexo hidrográfico formado pelos rios Mogi-Guaçu e Pardo, exemplares albinos de 


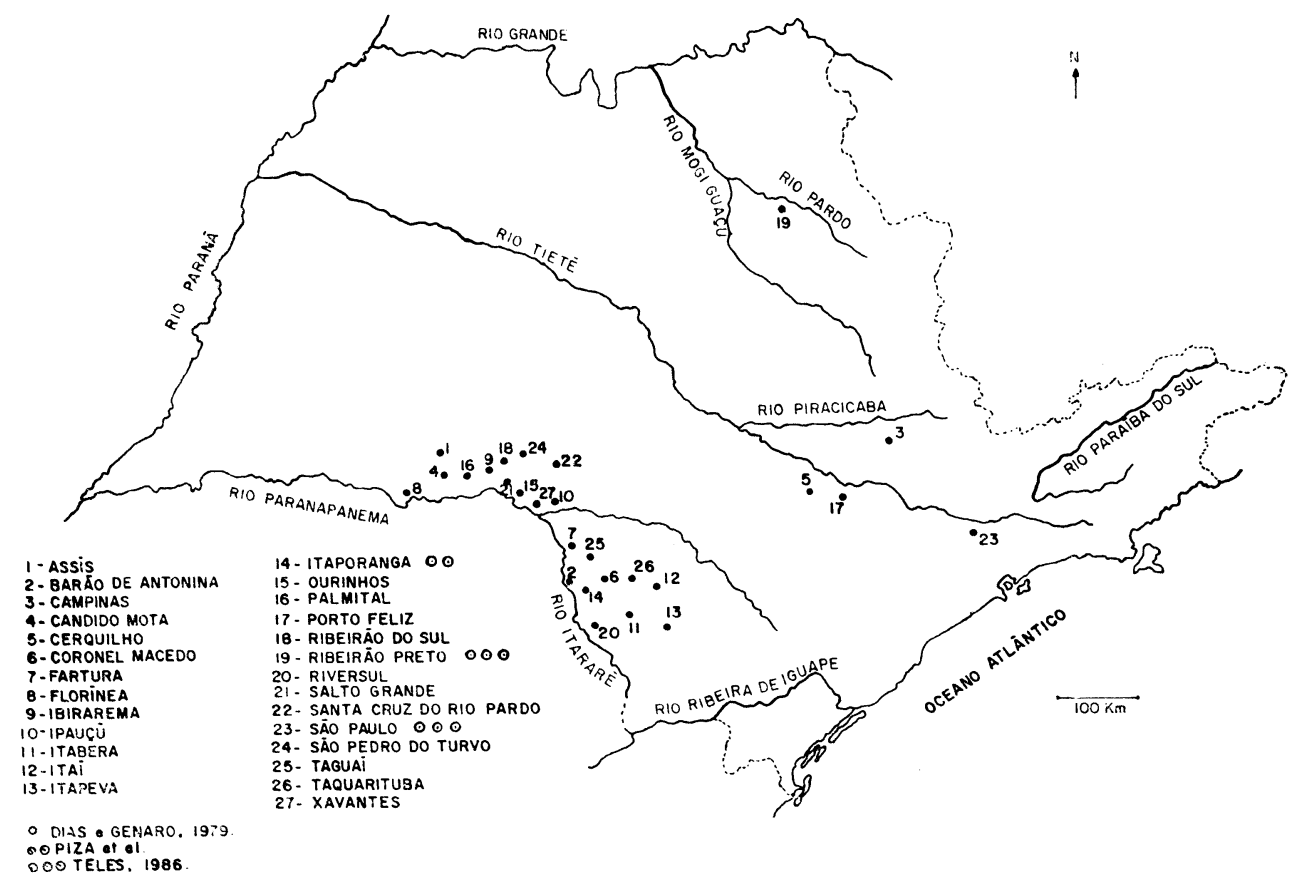

Fig. 1 . Municípios com criadouros de Biomphalaria glabrata localizados no período de setembro de 1981 a novembro de 1986.

B. glabrata advinham de um aquário doméstico e foram adquiridos em uma loja local especializada em artigos para piscicultura. Nenhum outro lote coletado em condições naturais na região mostrou exemplares da espécie.

Os municípios situados nas regiōes cortadas pelos rios Ribeira de Iguape, Paraíba do Sul e seus afluentes não tiveram criadouros identificados com este hospedeiro da esquistossomose mansônica.

\section{COMENTÁRIOS}

Comparando os resultados aqui obtidos com aqueles publicados por Piza e col. ${ }^{12}, B$. glabrata deixou de ser assinalada no presente para os municípios de Itaporanga e Florínea, contudo passou a figurar em criadouros de Barão de Antonina, Itaí, Palmital, Porto Feliz, Riversul, Ribeirão Preto, São Paulo e São Pedro do Turvo. Ao considerar relatos anteriores (Dias e Genaro ${ }^{4}$ e Teles ${ }^{15}$ ), o Estado de São Paulo dispõe de 27 municípios onde $B$. glabrata já foi registrada.

Quanto ao não reencontro de criadouros do caramujo nos municípios de Florínea e Itaporanga, convém salientar que ambos estão posicionados na área colonizada por $B$. glabrata, o que suscita a necessidade de que sejam efetuadas mais coletas. E possível que no período em que se conduziram os trabalhos de campo nessas localidades, as condições gerais do ambiente não tenham favorecido o achado do caramujo.

E de notar que $B$. glabrata encontra-se amplamente distribuída pela bacia do Paranapanema no lado paulista, correspondendo à distribuição geográfica apresentada por Lobo e $\mathrm{Luz}^{8}$ e Lima e $\mathrm{Luz}^{7}$ para o norte do vizinho Estado do Paraná. Como em São Paulo, também no Paraná o caramujo não é registrado nos criadouros dos municípios localizados ao longo da região compreendida pelo Baixo $\mathrm{Pa}$ ranapanema. Esses autores apontam o lado paranaense colonizado por $B$. tenagophila, ao passo que Vaz e col. ${ }^{16}$ monstram o predomínio de Biomphalaria occidentalis Paraense, 1981. Tudo leva a crer que $B$. tenagophila tenha sido confundida com $B$. occidentalis na época, dada a semelhança observada entre as duas espécies. A perfeita determinação específica neste caso só se tornou possível com a publicação de Paraense?.

No que diz respeito ao encontro de $B$. glabrata nos municípios de São Paulo, Porto Feliz e Cerquilho, parece que a instalação definitiva do planorbídeo na bacia do Tietê está relacionada à introdução acidental ocorrida em São Paulo, na USP, anos atrás. O monitoramento das águas do Rio Pinheiros por recalque ora na direção da Represa Billings, sentido 
inverso ao natural, ora na direção do Tietê, gera condições de dispersão favoráveis para ambos os sentidos, através da concorrência de mecanismos hidrocóricos passivos, tais como, transporte de desovas e/ou adultos de B. glabrata aderidos à vegetação e detritos. A impossibilidade do aporte desse material entre São Paulo e Porto Feliz é o resultado da dominância de margens pedregosas e forte correnteza nesse trecho do Tietê. A observação justificaria o aparecimento de $B$. glabrata fora da área de colonização natural. Diante da possibilidade dos acidentes e da dispersão, os eventos de Campinas e Ribeirão Preto merecem acompanhamento minucioso. Corrobora a necessidade de vigilância, o fato que logo após a introdução desta espécie de hospedeiro de $S$. mansoni na USP, Campos ${ }^{2}$ descobriu um caso autóctone de esquistossomose no local, com a transmissão associada a $B$. glabrata. Também a existência de uma área endêmica de considerável extensão, sobreposta aos domínios geográficos do caramujo em São Paulo $\left(\mathrm{SUCEN}^{14}\right)$, indica grande potencial epidemiológico para esta espécie no Estado.

\section{CONCLUSOESS}

1 - Biomphalaria glabrata ocorre em criadouros localizados em 24 municípios do Estado de São Paulo: Assis, Barão de Antonina, Cândido Mota, Cerquilho, Coronel Macedo, Fartura, Ibirarema, Ipauçu, Itaí, Itaberá, Itapeva, Ourinhos, Palmital, Porto Feliz, Ribeirão do Sul, Ribeirão Preto, Riversul, Salto Grande, Santa Cruz do Rio Pardo, São Paulo, São Pedro do Turvo, Taguaí, Taquarituba e Xavantes.

2 - O encontro de populaçōes de $B$. glabrata em municípios situados ao longo do Rio Tietê fornece elementos que permitem caracterizar a possivel dispersão da espécie, portanto, é conveniente que as pesquisas planorbídicas sejam estendidas para outros municípios ribeirinhos.

3 - Dada a importância epidemiológica de $B$. glabrata para a esquistossomose, deve-se intensificar o exame dos caramujos e o diagnóstico de casos humanos na região de distribuição natural da espécie.

TELES, H. M. S. \& VAZ, J. F. Notes on the distribution of Biomphalaria glabrata (Say, 1818) (Pulmonata, Planorbidae) in the S. Paulo State, Brazill. Rev. Saúde públ., S. Paulo, 21:508-12, 1987.

ABSTRACT: It is reported the present distribution of Biomphalaria glabrata (Say, 1818 ) in the $S$. Paulo State. The presence of this intermediate host of schistosomiasis is at the present time recorded in 27 municipalities. This snail had been identified as the most important transmissor of the disease in several places in Brazil. The probable dispersion mechanisms involved in the distribution of the snail are commented on.

UNTTERMS: Biomphalaria glabrata, geographical distribution. Schistosomiasis mansoni. Epidemiology surveillance.

\section{REFERENCIAS BIBLIOGRAFICAS}

1. ARTIGAS, P. de T. \& CAMARGO, L. S. V. de. Presença de Australorbis glabratus, no Vale do Rio Pinheiros, no campo da Cidade Universitária. Rev. Fac. Farm. Bioquim. Univ. S. Paulo, 3:339-41, 1965.

2. CAMPOS, R. Foco aut6́tone de esquistossomose no Município de São Paulo. Rev. paul. Med., 86:141, 1975.

3. CORREA, R. de R.; PIZA, J. de T.; RAMOS, A. da S.; CAMARGO, L. V. de. Planorbídeos do Estado de São Paulo: sua relação com a esquistossomose (Pulmonata, Planorbidae). Arq. Hig., S. Paulo, 27:139-59, 1962.

4. DIAS, V. S. \& GENARO, O. Encontro de Biomphalaria glabrata (Say, 1818) em criadouro situado no Campus da Unicamp. In: Congresso da Sociedade Brasileira de Para- sitologia, 4. $0^{\circ}$ Campinas, 1979. Resumos. Campinas, 1979. p. 107.

5. GUARTTA, O. F.; ALVES, V. P.; VAZ, J. F.; OLIVEIRA, V. L. de; ISHIHATA, G. K. Sobre a ocorrência de Biomphalaria glabrata (Say, 1818) (Planorbidae - Pulmonata Gastropoda) no Município de São Paulo. In: Congresso Brasileiro de Parasitologia, 6. Belo Horizonte, 1981. Resumos. Belo Horizonte, 1981. p. 209.

6. KAWAZOE, U. \& PINTO, A. C. M. Importância epidemiológica de alguns animais silvestres na esquistossomose mansônica. Rev. Saúde públ., S. Paulo, 17:345-66, 1983.

7. LIMA, E. C. \& LUZ, E. Mollusca, Planorbidae: sua distribuição no Estado do Paraná. Arq. Fac. Med. Univ. Paraná, 3:17-26, 1960. 
8. LOBO, A. G. S. \& LUZ, E. Contribuição ao conhecimento da distribuição geográfica dos planorbídeos do Estado do Paraná. Rev. bras. Malar., 6:545-54, 1954.

9. PARAENSE, W. L. Biomphalaria occidentalis sp. n. from South America (Mollusca, Basommatophora, Pulmonata). Mem. Inst. Oswaldo Cruz, 76:199-211, 1981.

10. PARAENSE, W. L.; ALENCAR, J. T. A. de; CORREA, L. R. Distribuição dos planorbídeos e prevalência da xistosomose mansoni no Estado do Espírito Santo. Mem. Inst. Oswaldo Cruz, 78:373-84, 1983.

11. PIZA, J. de T. \& RAMOS, A. da S. Os focos autóctones de esquistossomose no Estado de São Paulo. Arq. Hig., S. Paulo, 25:261-71, 1960.

12. PIZA, J. de T.; RAMOS, A. da S.; MORAES, L. V. de C.; CORREA, R. de R.; TAKAKU, L.; PINTO, A. C. de M. Carta planorbídica do Estado de São Paulo. São Paulo, Secretaria de Estado da Saúde, s.d.

13. REY, L. Primeiro encontro de planorbídeos naturalmente infestados por furcocercárias de $S$. mansoni no planalto paulista (Ourinhos). Rev. Clin. S. Paulo, 28:57-64, 1952.
14. SUPERINTENDENCIA DE CONTROLE DE ENDEMIAS (SUCEN). Situação da esquistossomose no Estado de São Paulo (Relatorio). São Paulo, Secretaria de Estado da Saúde, 1982.

15. TELES, H. M. S. Sobre o encontro de Biomphalania glabrata (Say, 1818), em dois municípios do Estado de São Paulo, Brasil. Rev. Saúde públ., S. Paulo, 20:242-3, 1986.

16. VAZ, J. F.; ELMOR, M. R. D.; GONÇALVES, L. M. C.; ISHIHATA, G. K. Resultados do levantamento planorbídico da área de Presidente Prudente - Estado de São Paulo. Rev. Inst. Med. trop. S. Paulo, 25:120-6, 1983.

17. VAZ, J. F.; TELES, H. M. S.; TAKAKU, L. Levantamento planorbídico do Estado de São Paulo: $7 .^{\mathrm{a}}$ Região Administrativa. Cienc. Cult., 37:2057-62, 1985.

18. VAZ, J. F.; TELES, H. M. S.; LEITE, S. P. da S.; CORREA, M. A.; DAL FABBRO, A. L.; ROSA, W. S. Levantamento plarorbídico do Estado de São Paulo: 6. ${ }^{\mathrm{a}}$ Região Administrativa. Rev. Saude públ., S. Paulo, 20:352-61, 1986.

Recebido para publicação em: 13/3/1987 Aprovado para publicação em: $27 / 8 / 1987$ 